\title{
Perspectives on the future of manufacturing engineering
}

R. H. F. Jackson, Director

Manufacturing Engineering Laboratory

National Institute of Standards and Technology

Gaithersburg, $M D$

(391) 975-3405

Remarks to DIISM 1998

Automation \& Robotics Research Institute, University of Texas at Arlington

May 18-20, 1998

Good afternoon. Thanks for inviting me to speak today. It's a pleasure to be here with this group of internationally respected scientists and engineers. I recognize some of you from my involvement in the Intelligent Manufacturing Systems Program.

In a sense, we are here to exchange perspectives on what is essentially the "One Trillion Dollar Question:" why isn't the world, in general, and the manufacturing sector, in particular, realizing the full range of benefits that the $\$ 1$ trillion global investment in information technology should buy?

Clearly, companies and consumers are benefiting to some degree. Why else would spending for information technology be increasing at an annual rate of 12 percent? At this rate, the world's information technology bill will double to $\$ 2$ trillion in less than seven years. That's a lot of money to spend on technology that still has a long way to go before it approaches its full potential.

So, we're meeting here in Texas to discuss how one sector of the world's economy-manufacturing, an extremely important sector and a major creator of wealth-can make the most of its investments in information technology. And the title of this conference-Design of Information Infrastructure Systems for Manufacturing-places the emphasis right where it should be: on infrastructure. 
Today, you can invest in the world's most advanced equipment to run the world's most advanced software applications, and you'll still end up with heartburn and lots of disappointment. Executives and managers of manufacturing operations still will complain:

- That the information they need is not what they have.

- That the information they have is not what they really need.

- And that the information essential to solving a problem is not available, at least not in a form that supports good, timely decisions.

Now look ahead to the extended enterprises of the future that we all like to talk about. Visions of $21^{\text {st }}$ century manufacturing anticipate seamlessly integrated collections of geographically separated suppliers and customers whose operations are synchronized like the movements of ballet dancers. Yes, I'm being facetious, but there is no shortage of hyperbole when talking about future manufacturing enterprises-about next-generation manufacturing.

So, let's get back to current day reality. Think about the difficulty of integrating information systems within companies, let alone across companies that span the globe. The current reality is that data often are more like confetti than strategic resources. Data structures are incompatible and information systems are unconnected.

Reality, dream.... Benchmark, aspiration.... What is, and what can be.

My point is simply this: We must think big. We must be ambitious in our longterm goals. We must aim for perfect functionality - and plug-and-play compatibility - and all the other -"ilities," such as interoperability, extensibility, scalability, portability, reconfigurability, and so on.

But we also must sweat the details. And in this arena, many of the key details take the form of standards. Standards are the brick and mortar of the information technology infrastructure that the manufacturing sector so clearly needs. Unfortunately, standards are lacking or are immature in many key areas. And sometimes the standards are so complicated, so broad in scope, that they take a decade to develop, a situation that won't work in the information age.

So a major challenge that we all face is making the standards system-and the standardization process-more responsive, more relevant, more in-step with technology trends and industry needs. If we don't, then decades from now, we may be repeating the prediction that futurist John Diebold made back in 1952. In his book Automation, Diebold wrote: 
"[T]he elements of the automatic factory are already with us; all that remains is to connect the proper instruments to the computer and attach our machines."

Professor David Dilts of the University of Waterloo in Canada quoted this passage in a presentation that he recently gave at NIST (National Institute of Standards and Technology). I found it to be instructive as well as cautionary - and worth repeating.

Part of the reason for the divide between vision and reality is simply that the technology isn't there yet—although, clearly, lots of progress has been made, especially within the last few years. Another part of the reason, I submit, is the gulf-maybe, wall is a better word-that stands between planning for manufacturing information systems and the other strategic and operational elements of manufacturing.

I think that we have reached—or, at least, are approaching —an advantageous point in the evolution of science and technology and in the evolution of manufacturing organizations. This is a point at which information technology will be organic to all facets of manufacturing. Several complementary trends, I believe, are converging on a threshold that will result in the full flowering of information technology in manufacturing.

\begin{abstract}
About NIST
Before I elaborate, I should provide you with some context--some background information on my organization, the National Institute of Standards and Technology. With this information, you should be able to judge how many grains of salt you might need to swallow with what I'll be saying about future directions in manufacturing technology and its applications.
\end{abstract}

NIST is part of the Commerce Department. We work with industry to develop and apply technology, measurements, and standards. That's our mission. And we carry it out through four major programs:

One is the Advanced Technology Program (ATP). The ATP is a competitive, costshared awards program for U.S. industry. It fosters and accelerates early-stage development of high-risk technologies--many of them with the potential significantly to improve manufacturing processes and capabilities on industry-wide scales. The chart contains a list of major project areas with a heavy manufacturing concentration.

Then, there's the Manufacturing Extension Partnership (MEP). This cooperative program is a nationwide network of technical assistance centers set up to help 
smaller manufacturers modernize their operations. One key thrust is to help these businesses develop the capabilities needed to become agile, high-performing suppliers that prosper in this dawning era of supply-chain-centered competition. MEP has 78 centers located throughout the U.S. with 300 field offices out of this network, and out of which more than 2000 field engineers operate.

The National Quality Program, the third element of NIST's portfolio, manages-with industry--the Malcolm Baldrige National Quality Award. Many people believe that the Baldrige Award is among our nation's best examples of effective cooperation between government and industry.

Finally, there's the NIST program of laboratory research and services, a job we've been doing for nearly 100 years. Our seven laboratories attend to the care, feeding, and development of the U.S. technology infrastructure.

This includes:

- measurement methods,

- calibration services,

- quality assurance capabilities,

- generic industrial technologies,

- software interface standards,

- accredited testing laboratories, and

- evaluated scientific data.

In important--but often invisible--ways, these products and services support your companies' performance in the laboratory, design shop, factory, and marketplace. And they're becoming increasingly crucial to trade.

In fact, the framers of the U.S. Constitution understood that, for efficient commerce, we need a trusted system of money and a trusted system to measure quantity and performance. Without these essential supporting elements, an economy can't move beyond the barter system.

For example, when we buy gasoline, we expect the volume of a gallon or liter to be the same at all stations. If we're willing to pay a premium price for higher octane, we assume there exits a measurement system that assures we get what we pay for. Or, if we're buying a new computer and are considering paying a higher price for a $330-\mathrm{MHZ}$ processor rather than a $233-\mathrm{MHz}$ processor, we assume there is a measurement system that can tell the difference.

The U.S. Constitution assigns responsibility for the nation's monetary and metrology systems to the Federal government, and these roles are carried out in similar ways. Banking is a private sector enterprise enabled by the Federal 
government. Functioning as a central bank, the government supplies currency, assures that the domestic system operates fairly, and fosters international acceptance of U.S. currency. In the same way, metrology is a private sector enterprise with the Federal government providing a central metrology function. The Federal government also assures that the domestic system operates fairly, and fosters international acceptance of U.S. measurements.

Through NIST, the Federal Government also expands and strengthens the measurement system as technology advances. And we all know that advancing technology is vital for commerce and international trade. It accounts for approximately $50 \%$ of U.S. economic growth. It drives demand for new measurements and standards. And it requires that NIST maintains state-of-the-art scientific facilities.

Consumer confidence in the marketplace depends on the measurement chain and the quality of our support of the fundamental units and the measurement infrastructure, and the leverage here is impressive. The annual investment in NIST is about $\$ 400 \mathrm{M}$, less than $.5 \%$ of all Federal R\&D (research and development). This undergirds $\$ 10 \mathrm{~B}$ per year in private sector investment in measurement and standards. And it impacts the U.S. economy in an astounding way: more than half of $\$ 7.6$ trillion per year U.S. GDP (Gross Domestic Product) is supported by measurement.

As an aside for those of you interested - all standards are derived from a few fundamental units. So, for example, acceleration is derived from length \& time, work is derived from length and force, and force is derived from mass \& acceleration. Also, each unit has an internationally agreed upon method for realizing and disseminating it through the measurement transfer chain, from basic units to those derived for everyday applications.

\section{Overview of Trends}

My job as director of the NIST Manufacturing Engineering Lab--a 400-person $R \& D$ and service operation--is the vantage point from which I'd like now to talk about several prospects for the future of manufacturing engineering.

I'll go out on a limb and talk about how collaboration can transform these trends into advanced manufacturing capabilities. But before I do, I'd like to show you this collection of remarks by people who have misread technology's tea leaves. It's been posted on scores of Web pages, so you may have seen it in one form or another. But the corollary to these off-target projections is a statement by the novelist John Galsworthy. He once reminded that, "If you don't think about the future, you can't have one." I can assure you that we at NIST are thinking about 
the future of manufacturing. And information technology plays a huge role in that future.

The first trend is the trend toward "science based" manufacturing and, especially mathematics-based manufacturing. In all facets of manufacturing and at every link in the value chain, trial and error is an increasingly costly way of doing business. Algorithms, process models, analytical methods, and the like have become critical enablers of superior machine tools, more efficient processes, advanced manufacturing capabilities, and better decision-making.

The second path is "integration." It's not the installation, but rather the integration of technology--and of technology and people--that delivers the decisive advantages and improvement gains that manufacturers seek in their capital investments. Yet, the dynamic nature of technological change makes integration an especially challenging task.

The third path is "information technology." Modern information technology is a dynamic force. It's creating an expanding bubble of capabilities and business opportunities that we've just begun to realize. It's catalyzing and enabling changes in the way companies organize, operate, collaborate, and compete. Today's notions of supply-chain management and virtual corporations are examples. Holonics and fractal manufacturing are two others.

Clearly, all three of these trends are related. Information technology, however, is the chief enabler and the chief source of competitive advantage. It is the technology that industries and companies-alone and together-will have to master, adapt, refine, and exploit.

\section{Science-Based Manufacturing}

My laboratory and all of NIST devote time, energy, and resources to anticipating the future needs of U.S. manufacturers. We have to.

Consider, for example, that over the last half century, dimensional tolerances have been shrinking tenfold every decade or so. State-of-the-art, high-precision products of the early 1980s are "off-the-shelf" today. For the laboratory charged with, among other things, maintaining the national standard of length--that's my lab, the NIST Manufacturing Engineering Lab--this progression is a real challenge. Our measurement capabilities must exceed industry's best--ideally by a factor of four.

The microelectronics industry is at the forefront of this relentless push. Eversmaller devices squeezed onto ever-faster and ever-more powerful chips, means that we at NIST must forever be splitting hairs--and splitting and splitting them. 
We're now at the point where we're developing measurement tools that are built molecule by molecule, and even atom by atom. We're also developing tools for making electrical measurements that count individual electrons.

Another way to look at this trend is with fire hoses. This slide shows two types of fire hoses and their connectors. One is a conventional fire hose; the other is an "information fire hose," an optical fiber, the conduit for voice communications and for sending huge amounts of data.

Shortly after NIST was founded as the National Bureau of Standards, a fire ravaged a 70-block area in the City of Baltimore. Engine companies came from as far away as New York to help. But most of these volunteers could only stand and watch because the threads on their hoses did not match the hydrants and other equipment at the scene.

In fact, the Bureau later determined that, at the time, there were more than 600 variations in fire-hose couplings. With the Fire Protection Association and another organization, NIST worked to develop specifications for a standard coupling.

In the optical fiber industry, a good connection also is critical. On the slide is a carefully manufactured fiber whose diameter has been measured, using this NISTdeveloped measurement reference. This reference is set to an unprecedented level of accuracy--about $35 \mathrm{~nm}$, or nearly one three-thousandth of the width of a human hair. This "SRM" (standard reference material) makes it possible to use selfaligning ferrules like the one shown here to link the wispy strands of optical fiber. It helps insure against a poor fit, that would impede signal transmission and, ultimately, upset customers. This reference material is a symbol of where much of industry is headed.

In all areas of advanced manufacturing--in discrete parts and continuous processing--there's an unquenchable thirst for higher levels of accuracy, precision, selectivity, and specificity. Consider, for example, that the longevity and reliability of car engines depend on manufacturing tolerances of micrometers--about the width of a single bacterium. The push for higher precision and greater accuracy is unrelenting. Why is that? Because improvements in these areas translate into higher quality, lower costs, less waste, better product performance, and happier customers.

Regardless of the industry, the competitive advantage goes to companies that can reliably manufacture and assemble parts and products to ever more exacting tolerances. The trend toward greater levels of precision and accuracy has several facets. One is the growing complexity of part geometry, which makes it doubly difficult to manufacture to tight tolerances. 
But complex shapes also offer advantages--special features that appeal to customers, higher levels of performance, or a single part that can do a job that was previously performed by combinations of two, three, or more different parts. The aerospace industry with its growing use of high-speed machine tools is a case in point. Companies are now machining large thin-walled parts that replace much heavier, riveted assemblies made up of many parts. Still, there's much to be learned before spindle speeds can be increased to $100,000 \mathrm{rpm}$ or even higher.

At NIST's High-Speed Machining Testbed, we're working with Boeing in St. Louis and Penn State to understand the dynamics of high-speed machining processes--with the aim of reducing them to mathematics, as opposed to trial-anderror experimentation.

I can report a couple of recent accomplishments in the high-speed machining area. With Boeing, our researchers have demonstrated the concept of tool tuning in high-speed milling. By explaining the dynamics of "regenerative chatter"--which occurs when a tool cuts over a surface that already has been cut--we have developed methods to stabilize the tool at a specified set of operating parameters. This has allowed us to take advantage of the full range of speeds that these machines offer.

Progress also has been made in the area of high-speed spindles, thanks in large part to funding from NIST's Advanced Technology Program. Matching funds from the ATP enabled the National Center for Manufacturing Sciences (NCMS) to mount what NCMS believes to be the first substantial spindle research program. The ninecompany collaboration has yielded promising prototypes of spindles that are fast, flexible, and compact. Two-HydroSpindle and TurboTool ${ }^{1}$--have won R\&D 100 awards. They're based on the same underlying technology. HydroSpindle maintains cutting accuracy up to speeds of $60,000 \mathrm{rpm}$, and it's nearing commercialization. The other spindle, TurboTool, has farther to go, but Aesop, the company that developed the technology is aiming for speeds of $100,000 \mathrm{rpm}$ with continuous power of $100 \mathrm{kw}$.

At NIST, a number of projects--past, present, and future--have been designed with the aim of improving machine tool capabilities. Many fall squarely within the domain of "science-based manufacturing."

Software error correction is one of the longest running lines of research in my laboratory, and this research has been especially useful to industry. When this work began, improving the performance of coordinate measuring machines and machine tools almost always required making expensive changes in the design, physical construction, and mechanical workings of the equipment. At the time, industry considered the idea of software error correction too risky, and didn't pursue it. Now, after many generations of improvement in the performance and 
costs of computing hardware, software-based methods for improving machine and process performance are really coming on.

The potential of modeling and other software-based methods for improving machine-tool performance may reach full flower in this monster or in any of the growing variations of the still experimental hexapod machine tools. Hexapod technology--or, more broadly, parallel-design machines--represents a radical departure from traditional machine tool design. The jury is still out on whether it will live up to theoretical expectations, but one of the technology's principal virtues is that it's well suited for the Information Age. For hexapods, accuracy depends mostly on the control and coordination of the strut movements. This makes them very computer intensive, which could be an advantage. It's much easier to change software instructions to improve performance and correct errors than it is to change mechanical components.

Right now we're working with a handful of companies to characterize the performance of this machine and to develop evaluation methods. We participate in a Hexapod Users Group, which includes most of the makers of parallel machine tools, several prospective manufacturing users, Department of Energy laboratories, and a number of universities. Stay tuned. In the not too distant future, NIST intends to provide you with the option of checking out the technology from your desktop computer or workstation. More on this later.

\section{Integration}

Now, let's move from the brawn and sinew of machine tools on to the brains. Today, machine-tool control--in fact, industrial process control--is an area of intense interest. It's poised, I think, for remarkable advances, especially in two areas: closed-loop processing and open architectures.

Continuing progress in computers, sensors, software, and mathematical modeling presents incredible opportunities for predictive, closed-loop process control. You can already find some places where it's used. Not many, but a few, and they're likely to be proprietary, or highly customized systems, built with controllers and other components that have closed interfaces.

So, if a manufacturer wants to upgrade or revamp his system, add a new capability, or otherwise change it, he'd better have deep pockets and time to spare. He's either going to be locked into buying a product, often at a premium, from the maker of his controller--if it has the application he's after. Or, he may have to spring for customized system integration--the software equivalent of gum and baling wire, except that it's tremendously more costly. Then there's the problem of lugging the growing accumulation of one-of-a-kind legacy software into the future. 
All of us in this room recognize the value, the promise, and the potential of integration--not only at the level of process control, but in all facets of manufacturing operations. But, for the moment, let's stick to control--specifically machine-tool control. Ideas for new applications are everywhere, and prospects for new capabilities are tantalizing. There's been an explosion of innovation in the area of sensors and actuators, presenting amazing new possibilities for intelligent process control and even opportunities to innovate and to create value.

Yet, I'd bet that companies are devoting more resources to application maintenance than to pushing the envelope, or to pursuing new, more robust approaches to control. And when a company does venture into new application realms, its engineer or programmer becomes a modern-day Sisyphus, pushing this growing boulder of legacy software up the hill to the next highest level of automation. Like the cartoon character "Popeye," some companies are saying, "That's all I can stands, and I can't stands no more!" Their answer to all of the legacy software is, "open architecture"--not a classic Popeye response, I grant you. But a few years ago, this kind of response would have been considered just as fanciful as a cartoon.

We are, I believe, in the early stages of an evolution toward open architectures and standard interfaces for controllers. To add momentum, we at NIST are working with industrial partners to clear technical obstacles to "plug-and-play" interoperability. In business terms, what a shift from "closed" to "open" architecture means is a shift from a market with relatively few players to a diversified market--a situation that usually benefits the customer. That's how the U.S. automakers and major aerospace companies see the situation. We've worked with both types--at Boeing and at GM (General Motors). And we've worked with Mat Shaver, proprietor and sole employee of his garage-based machining operation outside of Baltimore. Think of him as representing a "tier four or five" supplier.

Researchers in my laboratory have developed a prototype open-architecture controller. It serves as a testbed for evaluating standardized interfaces designed to accommodate interchangeable hardware and software components. Now, with a PC-based controller and standard interfaces, Mat Shaver, for example, can comparison-shop. He can search for the best value.

That's a significant advantage. He told us that a 40-megabyte hard disk from a controller vendor sells for about $\$ 1,700$. When he first contacted us, an 850 megabyte, floor-hardened disk drive for a personal computer sold for about $\$ 300$, which was 20 times the capacity for less than one-fifth of the price. Now you can get 1.5 gigabytes for about $\$ 300$, and that's about 40 times the capacity for less than one-fifth the price. And you just know it won't stop there. 
Multiply these prospective savings, and it's no surprise that some manufacturers have begun to push for open architectures. The "Big 3" U.S. car manufacturers and their aerospace counterparts have formed the Open Modular Architecture Controller (OMAC) Users Group to develop specifications for software interfaces, or application programming interfaces.

The job of developing these candidate interfaces has been assigned to a working group of industry and government engineers and scientists, including several from NIST. Besides members of the OMAC Users Group, our collaborators have included Advanced Technology and Research Corp., a company that recently introduced an open architecture controller based on the NIST work, and Real Time Innovations, a company that sells a software development tool that can be used for designing open architectures.

To further this evolution, we will continue to focus on measurements and tests for evaluating and validating prototype standards. We're concentrating on priority applications identified with the guidance of industry groups, including a consortium we formed last year. And as standards are formalized, we will develop tests and tools that will help controller manufacturers and software vendors ensure that their products conform with standards, a role NIST has performed for nearly 100 years.

In the controller area, the interfaces that ultimately do achieve broad industry acceptance will likely be a combination of market-dictated choices and standards crafted by consortia and formal standardization bodies. Because of the diversity of industries and needs in the manufacturing sector, several standard controller architectures may result. But we're heading in the right direction--from what was once dismissed as a manufacturing pipe dream toward controllers with software 'hooks' that enable competent programmers to affect real-time control processes.

This is a matter of great strategic importance to manufacturers all over the world, as indicated by standard architecture initiatives mounted in Europe and in Japan. Clearly, it is in the self-interest of companies to be active in the standards arena. Through their participation, companies can ensure that the resultant standards work to their advantage -- or, at least, not to their disadvantage.

This is especially important in light of the fast pace of change in technology in today's global economy. International standards are no less critical today than yesterday. International standards facilitate trade; national standards in many cases are barriers to trade. With technology changing so fast, we need to find new, more efficient ways to agree on standards and establish mutual recognition of traceable measurements. And we need to work together to accomplish this. 


\section{Information Technology}

If spending patterns are any indication, American industry is in love with information technology (IT). According to one 1996 estimate, U.S. companies spent more than $\$ 200$ billion on IT hardware alone-- "more than they invested in factories, vehicles, or any other type of equipment." When software, networks, support and maintenance, training and other related expenses are taken into account, U.S. industry's total IT bill is about $\$ 500$ billion.

What's motivating industry's spending binge on all this information technology-on all this "cool" stuff? A vice-president from a very, very large software company explained it this way to a Silicon Valley audience: "Cool, is a powerful reason to spend money." I suspect there's a not-so-small grain of truth here. But obviously, the primary motivators are:

- gains in productivity,

- greater customer-responsiveness,

- better performance,

- new organizational and manufacturing capabilities, and

- competitive advantages.

Although many companies use their IT tools quite skillfully, on the whole, industry's investment in IT is not yielding full value. In large part, this is because we lack the means flexibly to integrate processes, functions, systems, and companies on small and large scales.

For example, our research shows that, today, there are more than 400 software products billed as manufacturing and production engineering tools. Some of these simulation, modeling, and other engineering support tools are powerful applications for a particular function or a small set of functions. But these tools are largely incompatible with one another. Engineers re-enter data as they move back and forth among applications, which can lead to errors or to decisions made on the basis of information that's out-of-date or just plain wrong.

How much more useful these applications would be to your engineers--and to your business--if they were part of an integrated manufacturing tool kit. Regularly updated data would flow seamlessly among various software applications within a common computing environment. Elements of a shared database would range from production-system requirements to product, process and equipment specifications and from cost estimates and budget spreadsheets to plant layouts and set-up illustrations.

In fact, we're working with the users and makers of production-engineering software to develop and demonstrate a prototype integrated environment. 
Participating companies include Black and Decker, Boeing, Raytheon, Deneb Robotics, Cim Technologies, and Adra Systems. Several government programs and universities also are involved. Later this afternoon, you'll hear about one aspect of this research from Rangan Krishnamurthy. Last year, he worked as a guest researcher in the Manufacturing Systems Engineering Group in my laboratory.

So, with regard to manufacturing applications of information technology, we have a vision that we're pursuing in our laboratories and with our collaborators. It's a shared vision. And the National Research Council captured this vision best, perhaps, in a study from which we get this quote:
"The vision for 21st-century manufacturing presumes that interconnecting manufacturing applications will be as simple as connecting household appliances--one need only know how to run the application . . . and manage the interface ... The ease of interconnection and interoperation extends from devices found on the factory floor to applications connecting the factory to the product design facility to applications connecting an enterprise to its suppliers and customers ..."

We're pursuing this vision through our National Advanced Manufacturing Testbed (NAMT). The NAMT really is about the future, about building the technical means to make the most of advances in the performance of computing, communication, and networking technologies. This is a job that must be tackled collaboratively, and the NAMT is designed to facilitate that kind of effort, in the style of the next phase of the Information Age.

With industry's guidance, we've designed the NAMT to serve as a vehicle for building information-based-manufacturing's equivalents of roads, bridges, interchanges, and even mass transit rails. It's a multi-node, multi-project testbed, built on a state-of-the-art, high-speed computing and communications infrastructure. NIST serves as the "virtual host" to remotely located collaborators from companies, universities, and government laboratories located around the country. Through the NAMT, for example, you will be able to evaluate a new control algorithm on the NIST hexapod, while sitting at the computer in your laboratory or home office.

We're addressing real manufacturing problems here, but the solutions must meet a requirement that goes beyond the immediate "fix." By that I mean all projects must yield solutions that are modular, integratable elements of larger systems. In so doing, NAMT research and demonstrations will contribute to an open set of standards, interfaces, architecture specifications, and other infrastructural elements that enable varied sets and subsets of manufacturing systems to work together. 
Here's an example, the focus of a newly begun consortium. The objective is to develop the basis for virtual machine tools and inspection machines--computer models that behave exactly like the real McCoys on the factory floor. That capability would go a long way toward eliminating the communication gap between design and manufacturing, and shortening cycle times. You could cut digital bits before you cut metal to make certain that the first real part you make will be within specs.

Think of it: you'd be able to optimize use of your own machinery. Manufacturers would be able to avoid costly, eleventh-hour surprises, like the unexpected need to build new tooling or change a design. And, you'd be able to assess accurately whether prospective suppliers have the resources and capabilities to deliver parts that are within design specs.

What do we have to do to reduce virtual machining and inspection to industrial practice? We need to develop tools and standardized building blocks. We need computer models that represent actual machine behavior, mathematical representations of part geometry, more powerful machining and inspection algorithms, common data formats, and remotely accessible performance-data repositories. These will be the outputs of NAMT research, and many will be offered as the starting points for industry standards. That's an essential feature of the NAMT.

The value of information technology lies largely in connections, in links between applications, resources, and facilities. This is why NAMT projects emphasize developing the means quickly to assemble and reassemble these linkages. This is also why collaboration is so essential. Standards are the means to achieve interoperability, modularity, and reconfigurability, but they cannot be developed in isolation. This is the unifying theme of the projects already under way at the NAMT and of those yet to come.

The promise of information technology for manufacturing is, in fact, bright. But there are clouds. I've mentioned a few--lack of interoperability, bulky legacy applications and data, and costly maintenance. Looming even larger on the horizon is the question of whether smaller manufacturers--suppliers--will have the wherewithal to embrace and deftly apply advanced Information Age technologies. If suppliers don't join OEM's (original equipment manufacturer) in making the transition to information-based manufacturing, the benefits realized from investments in IT may be marginal.

I'll conclude with a rather pedestrian observation: What I find most noteworthy about modern manufacturing is the sheer and growing diversity of its parts, even as the larger companies cull their tiers of suppliers. The business of manufacturing has evolved from the equivalent of one-man bands and simple combos to 
incredible orchestras that play on a world stage. To be sure, the capabilities of individuals and their instruments remain important. But the tuning, the timing, and the arranging of a vast number of contributors are now absolutely critical to the quality and success of the performance. Today, it's not enough to be a virtuoso in one domain. This means that while building their proficiencies and investing in their own instruments, manufacturers must also think like they're members of orchestras. While paying attention to the overall score, they must also attend to the details of how best to perform with others, like--for example--developing the interface standards that will enable each participant in a distributed manufacturing enterprise to enter on time, and on key.

I've already strained the analogy, I know. But information technology, I believe, is fundamentally changing the ecology of business, redefining the nature of competition, and placing a high premium on cooperation. Often in the arena of information technology, we'll discover that what is good for all performers, can be even better for one. It will be best, however, for the firms that are most skilled and most savvy in understanding all aspects of the performance.

Thank you for listening and my best wishes for an excellent meeting.

' Certain commercial equipment, instruments, or materials are identified in this paper in order to specify the experimental procedure adequately. Such identification is not intended to imply recommendation or endorsement by the National Institute of Standards and Technology, nor is it intended to imply that the materials or equipment identified are necessarily the best available for the purpose. 